\title{
Prepontine Cistern
}

National Cancer Institute

\section{Source}

National Cancer Institute. Prepontine Cistern. NCI Thesaurus. Code C33397.

An area within the subarachnoid space, located between the arachnoid mater overlying the upper clivus and the anterior surface of the pons, that contains many blood vessels, including the basilar artery. 